\title{
УДК 159.09.07
}

\section{EVALUATION OF DIFFERENTIATING AND SMALL CHANGEABLE IDENTITY CATEGORIES OF TEACHERS ОЦЕНКА ДИФФЕРЕНЦИРУЮЩИХ И МАЛОИЗМЕНЯЕМЫХ КАТЕГОРИЙ ИДЕНТИЧНОСТИ ПЕДАГОГОВ}

Kolinichenko I.A. / Колиниченко И.А. Associate Professor, Ph.D. in Psychology/канд.психол.н, дои. ORCID:0000-0002-0644-6076 SPIN-code:7701-7240

Bondarenko E.I./ Бондаренко Е.И. ORCID:0000-002-4710-0055

Pyatigorsk State University, Pyatigorsk, Kalinin, 9, 357501 Пятигорский государственный университет, Пятигорск, Калинина, 9, 357501

\begin{abstract}
Аннотация. Предметом настоящего исследования является определение оценки дифференцирующих и малоизменяемых категорий идентичности педагогов - воспитателей дошкольных образовательных учреждений.
\end{abstract}

Исследование ставит своей иелью выявить отношение к религиозности людей, являющихся представителями одной профессии, но принадлежащчих к разным культурам. Для реализации научного замысла была применена психодиагностическая методика опросник М. Куна-Маркпатленда «Тест двадцати утверждений», модифицированная профессором Е.В. Ульгбиной.

Научная идея в рамках данного исследования заключается в том, чтобы выявить и показать отношение к религиозности воспитателей как субъектов образования и место этих взглядов в структуре идентичности. Актуальность исследования позволяет внести ясность в понимание людьми друг друга при налаживании эффективного диалога, в частности, среди коллег с разным уровнем отнотения к религиозности.

Результаты исследования показывают противоположные взгляды между группами воспитателей, но с небольшим количеством различий, которые объясняются идентичностью испытуемых с представителями одной культуры, хотя и с разной оченкой религиозности. Однако это не означает противостояние или оппозицию в их межличностных отношениях и вопросах воспитания детей благодаря общепринятым межкультурным ценностям, присущим любому цивилизованному обществу.

Ключевые слова: педагоги - воспитатели дошкольных учреждений, отношение к религиозности, нравственно-цеенностная проблематика идентичности, дифференцирующие категории идентичности, малоизменяемые категории идентичности.

Современные научные подходы к таким наукам, как социальная психология, нейропсихология и эволюционная психология обозначили новый путь к пониманию индивидуального и социального поведения личности. Концепция становления личности предполагает овладение умением строить межличностные отношения; формирование когнитивного развития жизненных навыков, критического мышления, этических и моральных норм поведения и пр., то есть всего того, что, по сути, включает в себя социальное и эмоциональное обучение.

Передача духовных ценностей с учетом аспектов бытия и принятых в каждой из самобытных культур правил и традиций является одной из важных задач современного педагога. Умение создавать личные позиции, 
соответствующие развивающимся культурным тенденциям, делая собственную идентичность непротиворечивой, необходимо для современного педагога в его отношениях с коллегами и воспитанниками. Несмотря на множество социальных ролей выполняемых личностью, она действует не только в соответствии со своими представлениями о них, но и с тем, какое значение они имеют в конкретной культуре.

Помимо обеспечения учеников качественными знаниями в обязанности педагога входит формирование у молодого поколения духовно-нравственных качеств, что, с одной стороны, зависит от зрелости и этических способностей самого педагога, a c другой, - накладывает на педагога определенные обязанности. Учитель не только является хорошим образцом для подражания, что очень важно, но и тем, что он ежедневно привносит в свои отношения с учениками, а именно, способность помочь им развивать моральное мышление без отрыва от своего морального авторитета.

Цитата Мартина Лютера Кинга "Intelligence plus character - that is the goal of true education” («Умственные способности плюс характер - вот цель настоящего образования») является основной идеей, которой следует руководствоваться педагогам. В своем выступлении в Гарвардской школе образования содиректор проекта The Making Caring Common Project высказал следующее: "What is the number one responsibility of teachers? Develop the moral values of students. Moral Teachers, Moral Students" (Что является ответственностью номер один для учителей? Развитие нравственных ценностей студентов. Нравственные Учителя, Нравственные Ученики») [1].

Понимание педагогом себя как личности представляет несомненный интерес для современной науки и практики, ведь педагоги в силу своей профессиональной деятельности, помимо умения передавать свои знания учащимся, должны также уметь оценивать свой человеческий потенциал и свою идентичность в структуре личностных и межличностных отношений.

Понятие «идентичность» представляет собой тождественность с кем-либо. Данный феномен достаточно загадочен, поскольку осмыслить и изложить его в простых категориях достаточно затруднительно. В строго научном определении данный термин означает принимаемый человеком образ себя, опосредованный отношением к социальной сфере, адекватным отношением к себе, постоянным и не изменяющимся от ситуации к ситуации.

Каждый субъект - это носитель только ему присущей идентичности, или идентичностей [6], его деятельностью управляют установки по отношению к той части социальной жизни, в которых он участвует.

В зарубежной психологии теория социальной идентичности возникла при попытках оценивания религиозных, этнических, национальных и других аспектов идентичности [3, 4]. Принципы теории социальной идентичности были известны еще в XX веке благодаря работам Г. Тэджфела, важное место в которых занимали представления о личностной и социальной идентичности как противоположных сторонах процесса идентичности. Научные взгляды Дж. Тернера на проблемы социальной идентичности выходят за рамки индивидуальной парадигмы в психологии, в них субъект предстает не как 
индивид, наделённый совокупностью ролей, а как элемент сообщества, обладая при этом идентичностью с ее особенным смыслом [9].

В психоанализе идентичность субъективно воспринимается как похожесть человека на свой образ «Я» и его непротиворечивость при его оценке другими.

Э. Эриксон, основатель эго-психологии, вклад которого в мировую науку связан с открытием им множественности термина «идентичность», считал, что эгоидентичность включена в единый социальный процесс, а психосоциальная идентичность представляет собой самотождественность личности [8]. По его мнению, рассмотрение тождественности становится возможным через призму индивидуального ресурса личностного развития, интуитивного и интеллектуального постижения личностного роста.

В отечественной психологии, в ее когнитивном направлении, идентичность представлена как специфически когнитивный инструмент, который используется индивидом с целью установления и категоризации социального окружения и своего места в этом пространстве [3]. Профессиональная ментальность педагога (В.А. Сонин) при рассмотрении его групповой, а именно, профессиональной идентичности помогает сформировать единый Я-образ, обнаруживающийся в личностно-компонентных явлениях, благодаря чему появляется потребность педагога в самоопределении [5].

Изучения идентичности с позитивным образом «Я» как проявления отношения к себе, а также вероятности принятия либо непринятия личностью изменений представляется значимым и требует дополнительных исследований.

Обоснование методики. Исследование проводилось на базе филиала Ставропольского государственного педагогического института в г. Буденновске. В исследовании принимали участие около 30 воспитателей дошкольных образовательных учреждений ставропольского края. Исследование и обработка данных проводилась доцентом кафедры психологии личности и профессиональной деятельности ФГБОУ ВО «Пятигорский государственный университет» г. Пятигорска И.А. Колиниченко.

Для реализации научного замысла было применено включенное наблюдение и психодиагностическая методика - опросник М. КунаМаркпатленда «Тест двадцати утверждений» [2]. Используемый в эксперименте опросник был модифицирован профессором Е.В. Улыбиной с учетом данных, полученных Э. Эриксоном, Х. Маркусом, И. Гоффманом, Р. Лифтоном $[7,8]$. Цель опросника заключалась в оценке дифференцирующих, малоизменяемых и групповых категорий идентичности.

\section{Проведение исследования}

Поскольку нравственно-ценностная проблематика идентичности, несомненно, затрагивает вопросы религиозности, нами было проведено исследование различий между группами испытуемых в зависимости от уровня их отношения к религии.

1) Сначала испытуемым предлагалось ответить на вопрос «Кто Я?».

2) После заполнения столбца № 1 (ответа на вопрос «Кто Я?») в столбце № 2 каждую отдельную характеристику предлагалось изменить по своему усмотрению и затем оценить по баллам (от 1 до 7 по восходящей). 
3) В столбце № 3 каждую из характеристик следовало оценить по степени ее желательности для испытуемого (те же баллы).

Следующим этапом явилось заполнение листов с демографическими данными, а также заполнение таблицы, в которой испытуемые должны были выразить свое отношение к религии (баллы 1-7 были прописаны заранее с обоснованием смысла каждого из них).

По результатам самооценки испытуемые были разделены следующим образом: в первую группу включили тех, кто приписал себе 2-4 балла по 7значной шкале отношения к религии, вторую группу составили испытуемые с уровнем, соответствующим оценке от 5 до 6 баллов.

После заполнения индивидуальных протоколов и подсчета результатов ответов у каждого испытуемого, полученные данные были внесены в сводную таблицу. Статистический расчет средних значений с помощью пакетов Statistica for Windows 8 проводился с применением непараметрического U-критерия значимости Манна-Уитни (табл. 1).

Таблица 1.

Различия в оценке характеристик идентичности личности

\begin{tabular}{|c|c|c|c|c|c|}
\hline \multirow{2}{*}{\multicolumn{2}{|c|}{ Показатели различий категорий }} & \multicolumn{2}{|c|}{$\begin{array}{c}\text { Выраженность ранга } \\
\text { в зависимости от } \\
\text { отношения к религии }\end{array}$} & \multicolumn{2}{|c|}{$\begin{array}{l}\text { Различия } \\
\text { между } \\
\text { группами }\end{array}$} \\
\hline & & Группа 1 & Группа 2 & $\mathrm{U}$ & \\
\hline \multicolumn{2}{|c|}{ Дифференцирующие } & 219 & 81 & 23 & \\
\hline \multicolumn{2}{|c|}{ Малоизменяемые } & 286 & 14 & 24 & $\curvearrowleft$ \\
\hline \multicolumn{2}{|c|}{$\begin{array}{l}\text { Изменяемость малоизменяемых } \\
\text { категорий }\end{array}$} & 275 & 25 & 25 & 要 \\
\hline \multirow{2}{*}{$\begin{array}{l}\text { Желательность } \\
\text { категорий }\end{array}$} & дифференцирующих & 226 & 75 & 36 & \\
\hline & малоизменяемых & 282 & 19 & 29 & \\
\hline
\end{tabular}

Примечания. U-критерий Манна-Уитни, $p$-уровень значимости.

\section{Результаты исследования}

Различия по критерию дифференцированной идентичности больше выражены у испытуемых Группы 1 с невысокими показателями отношения к религиозности в отличие от испытуемых Группы 2.

На статистически значимом уровне результаты различаются также по малоизменяемым категориям идентичности и выше - также в Группе 1. Возможность изменений категорий идентичности (малоизменяемых) больше выражена в Группе 1 на среднем уровне значимости. Желательность дифференцирующих категорий на достоверном уровне значимости также больше выражена в Группе 1 с невысоким уровнем отношения к религиозности, как и желательность малоизменяемых категорий.

На основании полученных результатов, у испытуемых с меньшей оценкой отношения к религии выявилась следующая закономерность: направленность внимания на себя, как на личность, и на принадлежность к биологическим аспектам своей самости; возможность развития своих дифференцирующих и малоизменяемых черт. 
Воспитатели Группы 1оценивают вероятность перемен в своей жизни без участия внешних социальных институтов типа церкви, религии как авторитетов, больше полагаясь на себя, что включает элемент самодостаточности воспитателей с их личностными чертами, характером и биологической подструктурой структуры личности.

Исследование показало противоположные взгляды между воспитателями как представителями одной профессии, но с разным отношением к своей идентичности. Небольшое количество различий объясняется идентичностью испытуемых с представителями одной культуры, хотя и с разной оценкой религиозности, а также с идентичностью внутри единого педагогического сообщества, в данном случае, воспитателей дошкольных учреждений.

Через призму этих представлений возможно провозглашение разнообразных подходов к воспитанию детей, но это не означает противостояние или оппозицию между воспитателями. Правильное понимание культурно-мировоззренческих взглядов друг друга и принятие их педагогами с разным отношением к религиозности помогут внести ясность в решение проблем налаживания диалога в их межличностных отношениях.

\section{Литература:}

1. Бондаренко Е.И. Формирование духовно-нравственных ценностей как неотъемлемая составляющая учебного процесса на занятиях по английскому языку // Язык и культура в эпоху интеграции научного знания и профессионализации образования: Материалы II международной научнопрактической конференции. В 2 частях. Часть I. - Пятигорск: ПГУ, 2018. - С. 256-266.

2. Кун М. Эмпирическое исследование установок личности на себя / М. Кун, Т. Макпартленд // Современная зарубежная социальная психология: Тесты / под ред. Г. М. Андреевой и др. - М.: Изд-во МГУ, 1984. - С. 180-188.

3. Смолякова Т.В. Психологические особенности структуры профессиональной идентичности студентов, обучающихся в художественных вузах // Психологические исследования, 2014. - Т.7. - № 34. - С. 7.

4. Соколова Е. Т., Бурлакова Н.С., Лэонтиу Ф.К. К обоснованию клиникопсихологического изучения расстройства гендерной идентичности // Вопросы психологии, 2001. - № 6. - С. 3-16.

5. Сонин ВА. Психолого-педагогический анализ профессионального менталитета учителя // Мир психологии. 2000. - № 2. - С. 183-191.

6. Труфанова Е. О. Идентичность и Я // Вопросы философии, 2008. - № 6. C. 95-105.

7. Улыбина Е.В. Неизменность как характеристика идентичности футбольных фанатов // Психологические исследования, 2012. - Т. 5. - № 23. URL: http://psystudy.ru.

8. Эриксон Э. Идентичность: юность и кризис / под общ. ред. А. В. Толстых. - М.: Издательская группа «Прогресс», 1996. - 344 с.

9. Turner J.C. at.al. Rediscovering the social group: A self-categorization theory. Oxford, NY, 1987. 


\section{References:}

1. Bondarenko E.I. The formation of spiritual and moral values as an integral component of the educational process in English classes // Language and culture in the era of the integration of scientific knowledge and the professionalization of education: Materials of the II international scientific and practical conference. In 2 parts. Part I. - Pyatigorsk: PSU, 2018 .-- S. 256-266.

2. Kuhn M. An empirical study of personality attitudes toward oneself / M. Kuhn, T. MacPartland // Modern Foreign Social Psychology: Tests / Ed. G. M. Andreeva and others - M .: Publishing house of Moscow State University, 1984. - S. 180-188.

3. Smolyakova T.V. Psychological features of the structure of professional identity of students studying in art universities // Psychological research, 2014. - T.7. - No. 34. - S. 7.

4. Sokolova E. T., Burlakova N. S., Leontiu F. K. To the rationale for the clinical and psychological study of gender identity disorders // Psychology Issues, 2001. - No. 6. - P. 3-16.

5. Sonin VA. Psychological and pedagogical analysis of the teacher's professional mentality // World of Psychology. 2000. - No. 2. - S. 183-191.

6. Trufanova E.O. Identity and I// Questions of Philosophy, 2008. - No. 6. - P. 95-105.

7. Ulybina EV Invariability as a characteristic of the identity of football fans // Psychological Research, 2012. - V. 5. - No. 23. URL: http://psystudy.ru.

8. Erickson E. Identity: youth and crisis / under the general. ed. A.V. Tolstykh. - M .: Publishing group "Progress", 1996. - 344 p.

9. Turner J.C. at.al. Rediscovering the social group: A self-categorization theory. Oxford, NY, 1987.

Abstract. The subject of this study is to determine the assessment of the differentiating and little changeable categories of identity of teachers - educators of preschool educational institutions.

The study aims to reveal the attitude towards religiosity of people who are representatives of the same profession, but belonging to different cultures. A psychodiagnostic technique was used to implement the scientific plan - M. Kuhn-Markpatland's questionnaire "Test of twenty statements", modified by Professor E.V. Ulybinoi.

The scientific idea in the framework of this study is to identify and show the levels of religiosity of educators as subjects of education and the place of these views in the structure of identity. The relevance of the study allows us to clarify the understanding by people of each other while establishing an effective dialogue among, in particular, colleagues with different levels of attitude to religiosity.

The results of the study show opposing views between groups of educators, but with a small number of differences, which are explained by the identity of the tested persons with representatives of the same culture, although with a different assessment of religiosity. However, this does not mean confrontation or opposition in their interpersonal relations and in raising children issues due to generally accepted intercultural values inherent in any civilized society.

Key words: teachers - preschool teachers, attitude to religiosity, moral and value problems of identity, differentiating categories of identity, unchanged categories of identity. 